\title{
Profile of chronic kidney disease modifiable risk factors in a rural community of south east Nigeria
}

\author{
Adaobi I. Bisi-Onyemaechi, Henrietta U. Okafor and Maduka D. Ughasoro*
}

\begin{abstract}
Background: Chronic kidney disease (CKD) is on the increase globally. Prevention of this condition is ideal, however early detection of the disease becomes desirable where the disease process has begun as there are known interventions which can slow the progress to end stage renal disease (ESRD). This study aimed at detecting the profile of some modifiable risk factors for CKD in a cohort of household heads in a rural community with limited resources for managing chronic kidney diseases.

Methods: The study was conducted in a rural community in southeast Nigeria. One hundred and forty five household heads from randomly selected households were interviewed. Their blood pressures were taken and their urine tested. The data was analyzed using SPSS version 21. Simple frequencies and means were calculated.

Results: A total of 145 house hold heads were enrolled. Their mean age was 45.08 (19.65) years. Forty-seven percent had no prior knowledge of their blood pressure and $31.5 \%$ were found to be hypertensive. Only one study participant (1\%) had ever had a urinalysis test and proteinuria and glycosuria were found in 50.4 and $27.9 \%$ respectively. Most (75\%) patronized patent medicine vendors for their primary healthcare while 31.8\% had taken herbal mixtures in the past.

Conclusion: There are presently many modifiable risk factors for the development of chronic kidney disease in rural communities in south-east Nigeria. Urgent targeted intervention is required to forestall an epidemic of CKD in the near future.
\end{abstract}

Keywords: Risk factors, Chronic kidney disease, Rural community, Nigeria

\section{Background}

Globally, chronic kidney disease (CKD) prevalence has been noted to be on the increase both in children and adults [1]. Presently it affects $10 \%$ of the worldwide population with millions dying due to lack of access to treatment [2]. Worldwide over 2 million people receive treatment in form of dialysis or kidney transplant but this represents only $10 \%$ of the people who are dependent on it [3]. In England, according to a recent report published by NHS Kidney Care, chronic kidney disease costs more than breast, lung, colon and skin cancer combined [4]. This will have huge double burden of health and financial implications in places like sub Saharan Africa. There is a further variation in the prevalence of CKD between rural

\footnotetext{
* Correspondence: maduka.ughasoro@unn.edu.ng Department of Paediatrics, College of Medicine, University of Nigeria Ituku-Ozallam, Enugu, Nigeria
}

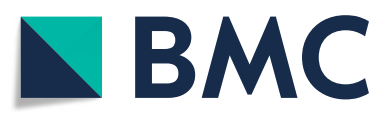

(c) The Author(s). 2018 Open Access This article is distributed under the terms of the Creative Commons Attribution 4.0 International License (http://creativecommons.org/licenses/by/4.0/), which permits unrestricted use, distribution, and reproduction in any medium, provided you give appropriate credit to the original author(s) and the source, provide a link to the Creative Commons license, and indicate if changes were made. The Creative Commons Public Domain Dedication waiver (http://creativecommons.org/publicdomain/zero/1.0/) applies to the data made available in this article, unless otherwise stated. associated with CKD is further compounded with lack of facilities and widely applied health insurance in resource poor countries.

Presently, there is a strong advocacy towards prevention of CKD achievable through some simple and easily available tools and strategies like routine monitoring of blood pressure, blood sugar and urine for infection. Unfortunately, most people with these CKD predisposing illnesses are not aware that they have these illnesses. Even people who have urinary tract infections (UTI) often take it to be malaria and treated as such $[5,6]$. Nevertheless, of all these predisposing illnesses one common finding is detection of protein in urine by simple urinalysis using test strip and this has been identified as one of the most reliable predictor of CKD in its early stage $[7,8]$. 
In view of the huge challenges of management of CKD and potential benefits of surveillance on the early symptoms and signs of the risk factors at the community level, it will be expedient to evaluate the extent to which communities watch out for these indices. In most African communities, the extent of awareness on health as well as their health-seeking behavior of the entire household is determine by the household-head's level of knowledge and awareness on health related issues [9]. It is usually one of the responsibilities of the house hold head to take decision on health related matters on behalf of other members of the household [10]. There are multitude of challenges that often confront decision making when a member of the household is ill [11, 12]. An evaluation of preventive healthcare being practiced by household heads with regards to rising prevalence of CKD would helpful in the design of preventive strategies and interventions for CKD. Thus in this study the researchers set out to ascertain the depth of information on risk factors for CKD and the prevalence of urinary abnormalities and other known risk factors of CKD amongst household heads in a rural community in Enugu.

\section{Methods}

\section{Study site}

The study was conducted in Mbogodo, a rural community in Nkanu West Local Government Area (LGA) in Enugu South-East Nigeria.

\section{Study design}

This was a cross-sectional descriptive study. A multistage sampling technique was used to select a community in Nkanu-West of Enugu state Nigeria. Study location was Mgbogodo, a rural community with a population of about 30, 000 for both adults and children, with estimated 590 households. There are average annual rainfall of $30 \mathrm{~cm}$ and maximum temperature of $35^{\circ} \mathrm{C}$. It has a tropical rain forest vegetation and malaria is holo-endemic in this region. The community is agrarian in nature with few female petty traders. There is a General hospital and a health center, both about $3 \mathrm{~km}$ away from the community.

\section{Sample size}

Three hundred and sixty four households were enumerated out of which 305 households were selected randomly to participate in the study. The decision to select 305 households was based on absolute response rate of 87 and 49.3\% for the first response and second response reported by Fekete et al [13] and, the targeted minimum sample size of 130 household heads. Since the study involved two stages: first, household selection and obtaining consent from the household heads to come to the health facility for the study and, the second step, which involved interview and investigation of the household heads that later presented to the health facility. Thus, $87 \%$ of 305 gave 265 households, and $49.3 \%$ of 265 produced 130 participants.

\section{Data collection}

The study involved two phases. The first phase was enumeration of the households in the community. The households that participated in the second phase were selected randomly from the list of the enumerated households. This was to ensure even selection and to prevent skewed of households that would participate in the study and give a better representation of the community. The selected households were revisited and researchers then created rapport with heads of the selected households explaining the purpose of the study as well as obtained consent to participate. They were then asked to visit the community health center for the second part of the survey- health facility-based clinical assessment and investigation. Since the survey was a component of a bigger study which involved laboratory investigations and anthropometric measurements, the selected households were requested to visit the health center for other aspects of the study. While in the health center, interviewer- administered semi-structured questionnaire which has both closed and open ended questions was used to obtain information on their age, educational status, knowledge of the symptoms of urinary tract infections, potential causes of kidney injury, prior knowledge of their blood pressure, previous history of having done a urine test, symptoms experienced in their previous illnesses and their health seeking behavior. The respondents were asked to select one major symptoms of UTI from a list of symptoms and the selected option was checked on the questionnaire, while they were asked to list conditions that can cause kidney injury and their responses written down on the questionnaire. They were allowed to mention as much as they could but only correct options were documented. For the urinalysis, The respondents were previously advised to take adequate water just before coming to the health centre. At the health centre, urine was collected from each of them in a universal container. Urinalysis was done immediately with Combi-9 rapid test kit and results were documented in case record forms. Standard practices were observed during blood pressure measurement. The measurement was taken $30 \mathrm{~min}$ later to allow adequate time for rest. Two different measurements of the blood pressures of the study participants were taken on the right arm in sitting position using Henson ${ }^{\mathrm{R}}$ mercury sphygmomanometer and the average documented subsequently.

\section{Data management}

Data management was done with SPSS software version 21 Chicago Illinois. Frequencies and means of continuous 
variables were found. Results of urinalysis done with the Combi 9 dipstick and the presence of protein was described in levels; negative, trace, $1+, 2+$, and $3+$. Proteinuria was taken as " $1+$ or more" reading on the combi urine test kit. Blood pressure was classified as normal: systolic blood pressure (SBP) $90-119 \mathrm{mmHg}$ or diastolic blood pressure (DBP) $60-79 \mathrm{mmHg}$, Prehypertension SBP 120-139 mmHg or DBP $80-89 \mathrm{mmHg}$ and Hypertension (HTN) was defined as SBP greater than $140 \mathrm{mmHg}$ and DBP greater than $90 \mathrm{mmHg}$ according to American Heart Association. Hypertension is further classified into Stage 1 HTN: SBP $140-159$ or DBP $90-99 \mathrm{mmHg}$, Stage 2 HTN: $\mathrm{SBP} \geq 160$ or $\mathrm{DBP} \geq 100 \mathrm{mmHg}$.

\section{Results}

One hundred and ninety eight household heads from the 305 selected presented to the health center, giving cooperation rate of $64.9 \%(198 / 305)$. A total of 145 household heads responded to the study, giving a consent rate of $73.2 \%(145 / 198)$ (Fig. 1). The mean age of the respondents was 45.08 years. Majority (68.3\%) were female. Those with secondary school education and above were $47.6 \%$, (Table 1 ).

Majority (58.6\%) of the respondents identified change in urine stream as a symptom of urinary tract infection, all other symptoms collected were only recognized by a small percentage $(41.4 \%)$ of the respondents. (Table 2) Most
Table 1 Socio-demographic Characteristics of the Respondents

\begin{tabular}{lll}
\hline Variables & $n=145$ & $\%$ \\
\hline Age in Years & & \\
$\quad$ Mean Age (SD) & 45.08 (19.65) & \\
Gender & & 68.3 \\
$\quad$ Female & 99 & 31.7 \\
$\quad$ Male & 46 & \\
Education & & 28.2 \\
No formal & 38 & 26.2 \\
Primary & 38 & 34.5 \\
Secondary & 50 & 13.1 \\
$\quad$ Tertiary;(University/College) & 19 & \\
\hline
\end{tabular}

mentioned hepatitis (62.1) as a cause of kidney disease while none identified hypertension as a cause of kidney injury.

The number of the respondents that had prior knowledge of their blood pressure was 61 (47\%.) The prevalence of hypertension among the respondents was $31.5 \%$ while $52.8 \%$ were pre-hypertensive. (Table 3 ).

Headache was the commonest symptom experienced during the last illness. (Table 4) Majority patronized patent medicine vendors during this illness while one person took herbal concoction. Only one respondent had ever done a urine test previously.

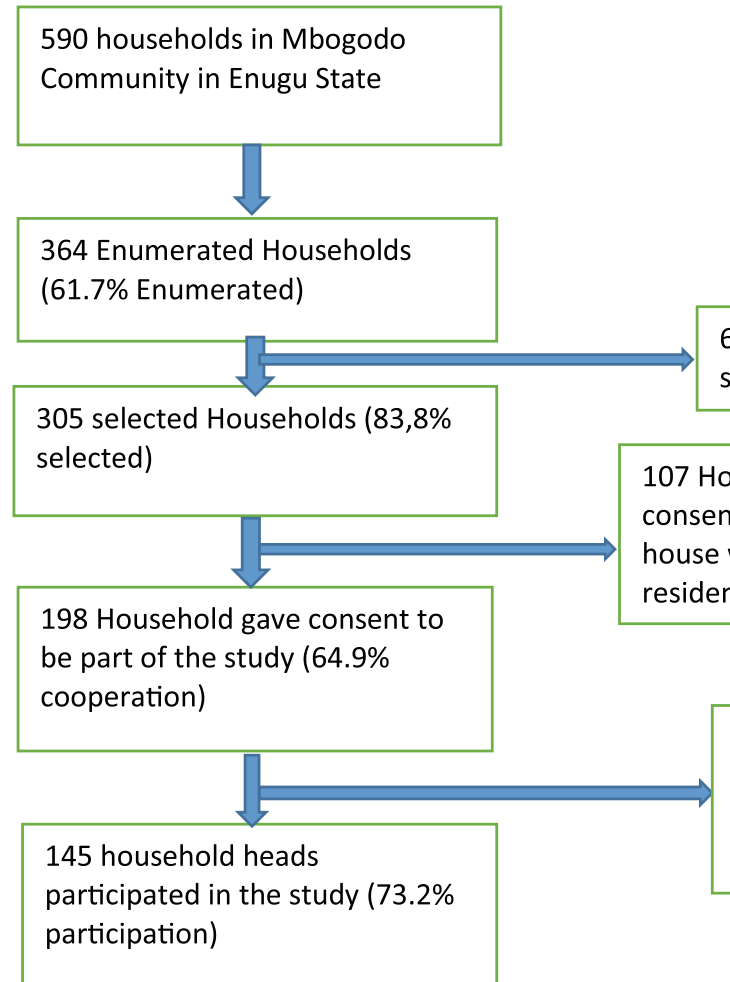

61 Households eliminated by simple random sampling

107 Households either did not give consent or nobody was found in the house when visited or the family was not resident in the rural community

53 Household heads gave their consent to participate in the study but did not present themselves to the health center

Fig. 1 Flow chart representing the selection of the household heads that participated in the study 
Table 2 The Respondents' Knowledge of Urinary Tract Infection

\begin{tabular}{lcc}
\hline Variables & $n$ & $\%$ \\
\hline Knowledge of Symptoms of Urinary Tract Infection $(n=143)$ & 85 & 59.4 \\
Change in Urine Stream & 21 & 14.7 \\
Urethral Discharge & 19 & 13.3 \\
Lower Abdominal Pain & 10 & 7.0 \\
Fever & 5 & 3.5 \\
Change in Urine colour & 2 & 1.4 \\
Dysuria & 1 & 0.7 \\
Back Pain & 0 & 0.0 \\
Vomiting & 90 & \\
Knowledge of Potential Causes of Kidney Injry & \\
Hepatitis & 90.1 \\
Kidney Injury & 31 & 21.4 \\
Diabetes & 26 & 17.9 \\
Malaria & 18 & 12.4 \\
Urinary Infection & 7 & 4.8 \\
Others & 12 & 8.3 \\
\hline asome respondents gave more than one response &
\end{tabular}

Protein was the most frequent (50.4\%) abnormality found in their urine, followed by glucose (27.9\%). (Table 5).

\section{Discussion}

There was an overall poor knowledge of symptoms attributable to kidney diseases among the respondents. This is similar to what has been reported in previous studies $[14,15]$. This finding is not peculiar with kidney diseases; there is an existing dearth of health knowledge even with other illnesses among the rural poor in Nigeria and most developing nations. This can be attributed to low literacy rates and subsequent poor utilization of

Table 3 The Blood Pressure Status of the Respondents

\begin{tabular}{lcc}
\hline Variables & $n=130$ & $\%$ \\
\hline Do you Know your Blood Pressure $(n=127)$ & \\
Yes & 61 & 47 \\
No & 69 & 53
\end{tabular}

Hypertensive based on Sphygmomanometer Measurement $(n=130)$

\begin{tabular}{cll} 
Yes & 41 & 31.5 \\
No & 89 & 68.5 \\
Pre-Hypertensive $(n=89)$ & 47 & 52.8 \\
Hypertension stage I & 18 & 43.9 \\
Hypertension stage 2 & 18 & 43.9 \\
Hypertension stage 3 & 6 & 12.2 \\
\hline
\end{tabular}

Normal blood pressure: systolic blood pressure (SBP) $90-119 \mathrm{mmHg}$ or diastolic blood pressure (DBP) 60-79 mmHg, Prehypertension: SBP 120-139 mmHg or DBP $80-89 \mathrm{mmHg}$ and Hypertension (HTN): SBP $\geq 140 \mathrm{mmHg}$ and $\mathrm{DBP} \geq 90 \mathrm{mmHg}$. Stage 1 HTN: SBP 140-159 or DBP 90-99 mmHg, Stage 2 HTN: SBP $\geq 160$ or $\mathrm{DBP} \geq 100 \mathrm{mmHg}$
Table 4 Health Seeking Behavior of the Respondents in their Previous IIInesses

\begin{tabular}{lcc}
\hline Variable & $N$ & $\%$ \\
\hline Action Taken During Last Illness $(n=125)$ & & \\
Visited Patent Medicine Vendor & 94 & 75.2 \\
Visited Hospital/Doctor & 17 & 13.6 \\
No Treatment Received & 10 & 8.0 \\
Prayed & 2 & 1.6 \\
Laboratory Test & 1 & 0.8 \\
Herbal Therapy & 1 & 0.8 \\
Previous Urine Test $(n=98)$ & & \\
Yes & 1 & 1.0 \\
No & 97 & 99.0 \\
Previous Ingestion of Herbal Concoction $(n=129)$ & 31.8 \\
Yes & 41 & 68.2 \\
No & 88 & \\
\hline
\end{tabular}

formal health care services as was observed in this study and previous ones [16-18]. The poor utilization of formal health service in this community could be due to distance of the health facilities to the community whose main mode of transportation is Also, poor flow of health information between health care providers and their patients/ clients during clinic visits contributes to low awareness of health issues even among the few privileged to access formal health care. This situation can be improved if there is a functional health system that aids quick and convenient presentation to the health facilities and health care providers inculcating the art of effective health communication and information sharing with their clients.

Table 5 Urinalysis results of the Respondents

\begin{tabular}{lll}
\hline Variables & $n$ & $\%$ \\
\hline Hematuria $(n=120)$ & 7 & 5.8 \\
Yes & 113 & 94.2 \\
No & 34 & 27.9 \\
Glucose $(n=122)$ & 88 & 72.1 \\
$\quad$ Yes & & \\
No & 62 & 50.4 \\
Proteinuria $(n=123)$ & 61 & 49.6 \\
Yes & & \\
No & 13 & 13.0 \\
Leukocyte esterase $(n=100)$ & 87 & 87.0 \\
Yes & & \\
No & & 4.1 \\
Nitrite $(n=121)$ & 5 & 95.9 \\
Yes & 116 & \\
No & &
\end{tabular}


Among the risk factors evaluated, most of the respondents had no prior knowledge of their blood pressure levels. Similar findings had been reported [19-21], and this is not unexpected in regions where access to formal health care for even overt health problems is low [22, 23]. Antenatal care [24] and immunization services [25] are the only preventive services not underutilized in this environment. Blood pressure measurement is routine for almost every health facility visit, therefore any visit to any tier of health service provider would likely improve this situation. The long term cost of this ignorance would be much considering the relative high prevalence of hypertension documented in this study. Similarly most have never had a urinalysis in the past in the face of high prevalence of asymptomatic proteinuria and glycosuria. This has also been documented in other studies.[26-28] Proteinuria and hypertension are known risk factors for chronic kidney disease. It has been widely shown that proteinuria may accelerate kidney disease progression to end-stage renal failure. Furthermore, glycosuria was detected in an appreciable number of respondents who were not aware that they were more likely to be diabetic. Since glucose appears in urine after a certain high threshold level of blood glucose is reached and well within diabetic range. Underlying the above situations are poverty and ignorance which has perpetuated some kidney risky practices such as use of herbal concoction for the treatment of illnesses as found in this study. The damaging effect of herbal concoction has been widely reported [29-32]. It is urgent to improve knowledge and practices considering the negative impact of the combination of poor knowledge of health status, use of herbal concoction and the high patronage of PMVs. These will eventually lead to late detection of any existing illness.

Patronage of patent medicine vendors for treatment of their illnesses is a common practice in Nigeria and other sub-Saharan African countries [33-35]. Onyeneho et al. [35] noted that $70 \%$ of their study participants patronize patent medicine vendors similar to the finding in this study. This practice may result from the belief that hospitals are reserved for "serious illnesses" as reported by some respondents. It may also explain the low prevalence of urinalysis among the study participants as the medicine vendors may lack the capacity to think beyond malaria when presented with certain symptoms. Hospital services include physical examination and laboratory investigations which help detect asymptomatic illnesses therefore affording time for early intervention and better outcomes.

A limitation in this study was the inability to examine the urine and check the blood pressure of other household members especially children. This information would have given insight into the prevalence of deranged urinary indices and hypertension among the paediatric population. Another limitation was, restricting respondents to one major symptom of UTI. They would have been allowed more options or the question left open ended. Expanding the options would have yielded more information on their knowledge on UTI and other symptoms associated with UTI. Furthermore, the lack of details (reasons, source, components, dosing and cost) of the ingestion of herbal concoction is a limitation on this study. With emerging evidence on the contribution of herbal mixtures to incidence of kidney injury, these would have been necessary.

\section{Conclusion}

Knowledge of kidney related symptoms was poor among the residents of Mgbogodo Southeast Nigeria. Majority had never done a urine test in the past. There was a high prevalence of high blood pressure in the population of which most were ignorant of. The services of patent medicine vendors were highly solicited in times of ill health. These are high risk factors for development of chronic kidney disease however they are all modifiable. Community health awareness and education programs may help in improving the health seeking behavior of this rural community to reduce or totally prevent the a rising prevalence of a possible CKD in future.

\begin{abstract}
Abbreviations
CKD: Chronic kidney disease; ESRD: End stage renal disease; LGA: Local government area; NHS: National health service; SD: Standard deviation; SPSS: Statistical package for social sciences; UTI: Urinary tract infection
\end{abstract}

\section{Acknowledgements}

The authors sincerely appreciate traditional ruler of Mgbogodo community and all the staff of Mgbogodo Health centre for their support towards the success of this study.

\section{Funding}

The authors have no relevant financial relationship relevant to this article to disclose. This research did not receive any specific grant from funding agencies in the public, commercial, or not-for-profit sectors.

\section{Availability of data and materials}

The datasets used and/or analyzed during the current study are available from the corresponding author on reasonable request.

\section{Authors' contributions}

$\mathrm{AB}$ contributed to initial conceptualization of the design, collection of data, writing of the initial draft and the final draft and approved of the final manuscript to be submitted. $\mathrm{HO}$ contributed to initial conceptualization of the design, contributed to the initial and final draft, and approved of the final draft. MU contributed to initial conceptualization of the design, analysed the data, writing of the initial draft and approving of the final manuscript to be submitted. All authors read and approved the final manuscript.

Ethics approval and consent to participate

This was obtained from both the National Health Research and Ethics committee and the Institutional Health Research and Ethics Committee of the University of Nigeria Teaching Hospital Enugu. Both verbal and written informed consents were obtained from household heads before they were enrolled in the study.

Competing interests

The authors declare that they have no competing interests. 


\section{Publisher's Note}

Springer Nature remains neutral with regard to jurisdictional claims in published maps and institutional affiliations.

Received: 2 November 2017 Accepted: 24 May 2018

Published online: 27 July 2018

\section{References}

1. Hill NR, Fatoba ST, Oke JL, Hirst JA ., O'Callaghan C, Lasserson DS, et al Global Prevalence of Chronic Kidney Disease. A Systematic Review and Meta-Analysis PLoS One | DOI :.https://doi.org/10.1371/journal.pone. 0158765, 2016:1-18.

2. Jha V, Garcia-Garcia G, Iseki K. Chronic kidney disease: global dimension and perspectives. Lancet. 2013;382(9888):260-72.

3. Couser WG, Remuzzi G, Mendis S, Tonelli M. The contribution of chronic kidney disease to the global burden of major non communicable diseases. Kidney Int Dec. 2011;80(12):1258-70.

4. World Kidney Day: Chronic Kidney Disease. 2015; http://www. worldkidneyday.org/faqs/chronic-kidney-disease/.

5. Federal Ministry of Health, National Malaria Control Programme, Abuja, Nigeria. Strategic Plan 2009-2013

6. Uzochukwu BSC, Onwujekwe OE, Okwuosa C, Ibe OP. Patent medicine dealers and irrational use of medicines in children: the economic cost and implications for reducing childhood mortality in Southeast Nigeria. PLoS One. 9(3):e91667. https://doi.org/10.1371/journal.pone.0091667.

7. Magdalena S, Madero M. Biomarkers in chronic kidney disease, from kidney function to kidney damage. World J Nephrol. 2015;4(1):57-73.

8. Król E, Rutkowski B, Czarniak P, Kraszewska E, Lizakowski S, Szubert R, et al. Early detection of chronic kidney disease. Results of the PolNef StudyAm J Nephrol. 2009;29(3):264-73.

9. Vallières F, Hansen A, McAuliffe E, Cassidy EL, Owora P, Kappler S, et al. Head of household education level as a factor influencing whether delivery takes place in the presence of a skilled birth attendant in Busia, Uganda: a cross-sectional household study. BMC Pregnancy Childbirth. 2013;13:48. https://doi.org/10.1186/1471-2393-13-48.

10. Angel-Urdinola, D, Wodon, , Income Generation and Intra-Household Decision Making: A Gender Analysis for Nigeria, MPRA Paper 2010, University Library of Munich, Germany, http://EconPapers.repec.org/RePEc:pra:mprapa:27738.

11. Dietrich C. Decision making: factors that influence decision making, Heuristics Used, and Decision Outcomes. Inq J/Stud Pulse. 2010;2(02):1-3. Retrieved from http://www.inquiriesjournal.com/a?id=180

12. Hajjaj FM, Salek MS, Basra MKA, Finlay AY. Non-clinical influences on clinical decision-making: a major challenge to evidence-based practice. J R Soc Med. 2010;103(5):178-87. https://doi.org/10.1258/jrsm.2010.100104.

13. Fekete $C$, Segerer W. Participate rates, response bias and response behaviours in the community survey of the Swiss spinal cord injury cohort study (SwiSCI). BMC Med Res Methodol. 2015;15:80

14. Oluyombo R, Ayodele OE, Akinwusi PO, Okunola OO, Gbadegesin BA, Soje MO, et al. Awareness, knowledge and perception of chronic kidney disease in a rural community of south-West Nigeria. Niger J Clin Pract. 2016;19:161-9.

15. Akpan EE, Ekrikpo UE. Chronic kidney failure: knowledge of kidney disease, perception of causes and symptomatology in Uyo, Nigeria. Open Journal of Nephrology. 2015;5:91-7. https://doi.org/10.4236/ojneph.2015.53014

16. Sudhinaraset $M$, Ingram $M$, Lofthouse HK, Montagu D. What is the role of informal healthcare providers in developing countries? A Systematic Review PLoS ONE. 2015;8(2):e54978. https://doi.org/10.1371/journal.pone.0054978.

17. Stock R. Distance and the utilization of health facilities in rural Nigeria. Soc Sci Med. 1983;17(9):563-70.

18. Barun -Kanjilal SM, Samanta T, Mondal A, Singh SA. Parallel health care market: rural medical practitioners in West Bengal, India. In: Institute of health management research; 2007.

19. Ahmed H.M, Ahmed Al Harthia, Hussam M, Ayman A.IJ, Noura A.I.T, Mohammed A.M.Awareness, attitude, and distribution of high blood pressure among health professionals: https://doi.org/10.1016/j.jsha.2012.10.002

20. Akindele YT, Ayankogbe $\mathrm{OO}$. Knowledge and awareness of high blood pressure in Ward F, Ifako-ljaiye local government area. S Afr Fam Pract. 2013:55(3):270-4.

21. Oliveria SA, Chen RS, McCarthy BD, Davis CC, Hill MN. Hypertension knowledge, awareness, and attitudes in a hypertensive population. J Gen Intern Med. 2005; 20(3):219-25. https://doi.org/10.1111/j.1525-1497.2005.30353.x

22. Titus OB, Adebisola OA, Adeniji AO. Health-care access and utilization among rural households in Nigeria. J Dev Agric Econ. 2015;7(5):195-203.
23. Chukwuneke FN, Ezeonu CT, Onyire BN, Ezeonu PO, Ifebunandu N, Umeora MC. Health seeking behaviour and access to health care facilities at the primary level in Nigeria: our experience. Ebonyi Medical Journal. 2012;11:1-2.

24. Duru CB, Oluoha UR, Uwakwe KA, Diwe EC, Merenu I, Chineke HN, et al. Antenatal care services utilization among women of reproductive age in semi-urban communities in Orlu LGA, Imo state Nigeria. Orient Journal of Medicine. 2015:27:1-9.

25. National Population Commission (NPC) [Nigeria] and ICF International. Nigeria Demographic and Health Survey 2013. Abuja, Nigeria, and Rockville Maryland USA: NPC and ICF International; 2014.

26. Braimoh RW, Akinkugbe AO, Ale OK, Balogun MR. Prevalence and pattern of urinary abnormalities among apparently healthy adult Nigerians. J Clin Sci. 2016;13:153-7.

27. Parakh P, Bhatta NK, Mishra OP, Shrestha S, Budhathoki S, Majhi S, et al. Urinary screening for detection of renal abnormalities in asymptomatic school children. Nephrourol Mon. 2012;4(3):551-5. https://doi.org/10.5812/ numonthly.3528.

28. Odetunde OI, Odetunde OA, Neboh EE, Okafor HU, Njeze NR, Azubuike JC Urinary screening for asymptomatic renal disorders in pre-school children in Enugu metropolis, south-East Nigeria: useful or useless. Saudi J Kidney Dis Transpl. 2015;26:1241-5.

29. Meyer MM, Chen T, Bennett WM. Chinese herb nephropathy. Proc (Bayl Univ Med Cent). 2000;13(4):334-7.

30. Akpan EE, Ekrikpo UE. Acute renal failure induced by Chinese herbal medication in Nigeria. Case Rep Med. 2015; https://doi.org/10.1155/2015/150204

31. Asif M. A brief study of toxic effects of some medicinal herbs on kidney. Adv Biomed Res. 2012;1:44. https://doi.org/10.4103/2277-9175.100144.

32. Ekor $M$. The growing use of herbal medicines: issues relating to adverse reactions and challenges in monitoring safety. Front Pharmacol. 2013:4:177. https://doi.org/10.3389/fphar.2013.00177.

33. Uzochukwu BSC, Onwujekwe EO, Onoka CA, Ughasoro MD. Rural-urban differences in maternal responses to childhood fever in south East Nigeria. PLoS One. 2008:3(3):e1788. https://doi.org/10.1371/journal.pone.0001788.

34. Uzochukwu BSC, Onwujekwe OE, Okwuosa C, Ibe OP. Patent medicine dealers and irrational use of medicines in children: the economic cost and implications for reducing childhood mortality in Southeast Nigeria. PLoS One. 2014:9(3):e91667. https://doi.org/10.1371/journal.pone.0091667.

35. Onyeneho NG, Amazigo UV, Njepuome NA, Nwaorgu OC, Okeibunor JC. Perception and utilization of public health services in Southeast Nigeria: implication for health care in communities with different degrees of urbanization. Int J Equity Health. 2016;15:12. https://doi.org/10.1186/s12939$016-0294-7$

Ready to submit your research? Choose BMC and benefit from

- fast, convenient online submission

- thorough peer review by experienced researchers in your field

- rapid publication on acceptance

- support for research data, including large and complex data types

- gold Open Access which fosters wider collaboration and increased citations

- maximum visibility for your research: over $100 \mathrm{M}$ website views per year

At BMC, research is always in progress.

Learn more biomedcentral.com/submissions 